\title{
Mandatory Planning for Environmental Innovation: Evaluating Regulatory Mechanisms for Toxics Use Reduction
}

\section{DARA O'ROURKE* \& EUNGKYOON LEE†}

\author{
*Department of Environmental Science, Policy and Management, University of California, \\ Berkeley, CA, USA \\ tDepartment of Urban Studies and Planning, Massachusetts Institute of Technology, \\ Cambridge, MA, USA
}

(Received May 2002; revised April 2003)

\begin{abstract}
This paper analyzes the Massachusetts Toxics Use Reduction Act (TURA), evaluating what TURA has achieved, how it has been implemented, how it motivates firms to change and how its underlying principles might be strengthened to better support innovation for toxics use reduction. Through this analysis recent debates are engaged about the potentials and limitations of using regulation to promote innovation for the environment. The analysis here shows that TURA is distinct from existing regulatory programmes in how it requires firms to self-evaluate and plan for process improvements, supports implementation through technical assistance and focuses on pollution prevention rather than control. Mandatory planning, new mechanisms of accountability and improved processes of learning have all been critical to TURA's success in motivating firms to innovate for the environment. Taken together, these factors have supported incremental innovations in industry that may point the way toward policies to support even greater environmental improvements.
\end{abstract}

\section{Introduction}

US environmental policies over the last 30 years have sought either explicitly or implicitly to spur innovations to resolve environmental problems (Ashford, 2002). Government programmes have been designed to motivate changes in production technologies to control, minimize or prevent pollution. However, despite this goal of supporting innovation, environmental policies in practice have taken on the broad features of what is now derisively called 'commandand-control' regulation, including defining 'best available control technologies' and requiring firms to install specific technologies to meet permitted pollution

Correspondence Address: Dara O'Rourke, Department of Environmental Science, Policy and Management, University of California, Berkeley, 135 Giannini Hall, \#3312 Berkeley, CA 94720, USA. Email: orourke@nature.berkeley.edu 
levels. These policies have come under fire for their inflexibility, high cost and perverse impacts of locking in existing technologies that may actually stifle innovation (Ackerman \& Stewart, 1985; Kraft, 1999; NAPA, 2000; Rondinelli, 2000).

Spurred by critiques of command-and-control regulation from all sides, a range of new policy options have been advanced to complement and supplement existing regulatory strategies and to strengthen incentives for innovation. One such trend involves 'information-based regulation' which seeks to spur reductions in industrial emissions by uncovering and disclosing information on pollution sources to industry managers, regulators and the public (Arora \& Cason, 1996; Karkkainen, 2001). By 1986, approximately 30 states had some form of pollution disclosure requirement on the books, and Congress had passed the Emergency Planning and Community Right-toKnow Act (EPCRA), which created a national database on toxic releases known as the Toxics Releases Inventory (TRI) (Hearne, 1996; Arora \& Cason, 1999).

A number of states have specifically experimented with public disclosure strategies and internal firm information systems that promote innovation in industrial practices. By the early 1990s, over a dozen states had passed laws requiring firms to use information on chemical uses and emissions to prepare toxics use reduction or pollution prevention plans. Among these initiatives is the Massachusetts Toxics Use Reduction Act (TURA) which uses information disclosure and mandatory planning to promote 'voluntary' industry innovations around toxic chemical reductions.

Despite important successes in promoting toxics reductions in the state of Massachusetts, TURA has received little analysis to date. TURA is a particularly interesting case as it is one of the first state-level initiatives to advance both ambitious goals for toxics use reduction and new policy strategies for achieving these goals. This paper seeks to explain the impact of TURA on toxics use reduction, to explore its underlying mechanisms and to theorize the potential for using policies of this kind to promote environmental innovation. Specifically, the paper examines what TURA has achieved, how TURA functions and how the underlying principles of TURA might be strengthened to better support innovation for toxics use reduction.

Through the analysis of TURA the paper also seeks to engage current debates about the potentials and limitations of using regulation to promote innovation for the environment. A number of analysts have proposed models for how environmental regulation can promote innovation and be more effective in the process. The most famous formulation of this idea is the 'Porter Hypothesis' (Porter \& van der Linde, 1995) which argues that the right kind of regulation can lead to competitive advantage for firms taking early and decisive action to improve 'resource productivity'. Ashford (2002) criticizes this limited view of 'innovation-friendly regulation' as motivating only incremental innovations in pollution control, arguing instead that regulation should drive 'radical innovation' through a Schumpeterian process of 'creative destruction'. Fiorino (2001) argues in a different direction that a key to moving forward in environmental policy and to spurring real innovation, requires developing policies for 'social learning' that move beyond specific strategies (such as market mechanisms and pollution prevention) to creating or realigning relationships to collectively solve environmental problems. 
Taken together, these analysts provide insights into strategies to support innovation by focusing on performance outcomes (rather than standards), mandating that firms conduct some form of self-evaluation and planning process, employ market incentives (such as economic cost-benefit analyses of technology options) and promote 'preventive' and proactive approaches to solving environmental problems. At a minimum, this literature argues that regulators can support firm innovations through technical assistance and pooling of learning among firms.

TURA is an excellent case through which to evaluate the central questions of this debate as the Act adopts several of the key features advocated by Porter, Ashford and Fiorino. But TURA also advances several principles not clearly delineated in existing regulatory theory. By analyzing the underlying mechanisms of TURA, a start can be made to generate hypotheses, admittedly preliminary at this time, on how regulation can motivate firms to innovate, how regulation can support learning within firms and among regulators and how regulation can support implementation of innovative environmental practices.

The paper begins by describing the history and implementation of TURA's distinctive planning and accounting systems, technical assistance mechanisms and decision-making support. The following section then examines the extent of the Act's success in motivating toxics use reduction between 1990 and 1999. This analysis is based on raw data provided by Department of Environmental Protection (DEP) and the Toxic Use Reduction Institute in Massachusetts, and interviews with staff of public interest groups, regulatory agencies and industry. The next section analyzes the dynamics central to motivating changes in firms-mandatory planning and learning supportwhich advance innovative action. This is followed by a discussion on some of the limitations of TURA. The final section concludes with preliminary policy recommendations for building on the central dynamics of TURA to better motivate environmental innovation.

Data used in this analysis are drawn from three sources. First, to measure the overall performance of TURA and to compare it with the Toxic Release Inventory (TRI), an analysis was made of raw data collected by Toxics Use Reduction Institute (TURI) and the US Environmental Protection Agency. Simple scatter plots are presented to compare TURA and TRI release data over time. The TURA data are normalized by analyzing a 'Core Group' of firms which includes only those industries and chemicals that remained within the reporting universe between 1990 and 1999. Because chemicals have been added and de-listed during the 1990s, and some TURA filers have entered or left the reporting universe due to changes in requirements, the sample is controlled to only include firms reporting over the life of the programme. This 'Core Group' accounts for approximately $60 \%$ of total toxic chemical use in Massachusetts (DEP, 2000).

A second data source includes survey data gathered by regulatory agencies and private research institutes. These data are analyzed primarily to assess firm attitudes towards TURA and stated rationale for changes in practices. Finally, a series of interviews were conducted with staff of public interest groups, regulatory agencies and industry organizations to explore hypotheses about underlying mechanisms influencing the functioning and effectiveness of TURA. 


\section{Overview of TURA}

In 1989, the Massachusetts legislature passed the Toxics Use Reduction Act (TURA) creating the Toxic Use Reduction Program. The Act, however, was not without controversy, as it was the product of extensive debate and negotiations between industry and environmentalists (Laden \& Gray, 1993; Becker \& Geiser, 1997). After considerable debate, the Act was jointly supported by both industry and environmentalists, passed unanimously by the state legislature and signed into law by the governor on 24 July 1989. Toxics Use Reduction (TUR) is defined in the Act as:

In-plant changes in production processes or raw materials that reduce, avoid, or eliminate the use of toxic or hazardous substances or generation of hazardous byproducts per unit of product, so as to reduce risks to the health of workers, consumers, or the environment, without shifting risks between workers, consumers, or parts of the environment (Toxic Use Reduction Act §2).

The primary objective of the Act was "to achieve by 1997, through toxics use reduction, a 50 percent reduction from 1987 quantities of toxic or hazardous byproducts generated by industry in the Commonwealth of Massachusetts"1 (TURA §13-A). To meet this objective, the legislation spells out how 'in-plant changes' can be achieved. Specifically, the Act establishes six TUR techniques: input substitution, product reformulation, production unit redesign or modification, production unit modernization, improved operations and maintenance and in-process recycling, reuse or extended use of production materials (TURA §2). It is worth noting that out-of-process recycling is not included as a toxics use reduction strategy.

According to the Act, large quantity toxics users (LQTUs) in certain industrial sectors ${ }^{2}$ must submit an annual toxic use reduction report, called a 'Form $S^{\prime}$, to the Department of Environmental Protection (DEP). The report is intended to identify production processes, the quantity of each listed chemical used, generated as byproduct or shipped as part of the finished product, and the percentage reduction of toxic byproducts and emissions. The percentage reduction is based on a base year that has been established by the firm. Large quantity toxics users must also pay an annual TUR fee to provide revenue for the regulatory agency to administer the TUR programme and to support a special trust fund for the TUR programme.

Finally, large quantity users must develop a biannual Toxic Use Reduction plan (or plan update) and submit a summary to the Department of Environmental Protection. The plan is required to include seven specific contents: a statement of facility-wide management policy regarding TUR, an assessment of how and in what quantities listed chemicals are used and generated as waste, an accounting of full costs of using those chemicals, a list of available TUR options, evaluation of feasible options, a description of options that a firm will employ, and an implementation schedule (TURA §11). To meet this requirement, LQTUs are encouraged by DEP to establish planning teams that analyze production processes, conduct materials balances, audit health and environmental effects and identify TUR options. Plans prepared by a firm must be certified by state-accredited TUR planners. A summary of the plan must be filed with DEP, and information about the TUR plan must be provided to employees. Once the 
mandatory TUR plan is filed, the programme becomes voluntary. In other words, firms decide whether they implement their plan in whole, in part or not at all.

TURA is distinct from other disclosure programmes in its system of toxics accounting, which it calls a 'materials balance'. This requires companies to assess the quantity of chemicals present in the entire production process, including the quantity of chemical substances transported to the facility, produced at the facility and transported from the facility as wastes or products. Materials accounting includes six throughput measures: "starting inventory, quantity of chemicals brought on-site, quantity produced on-site, quantity consumed in the production process, quantity shipped off-site as products, and ending inventory" (Hearne, 1996). By measuring chemicals at key points in the production process, a materials accounting system can provide crucial facility-wide information about toxic chemical use and industrial efficiency. Consequently, it provides facility managers, the government and potentially the public with valuable information to improve operations. Together with the requirement of a toxics use reduction plan, a materials accounting system contributes to a fuller and deeper assessment of toxic chemical use in a production process and potentially to alternatives for toxics use reduction.

TURA also mandated the Massachusetts government to establish six public institutions to support the goals of Toxics Use Reduction: the Office of Technical Assistance (OTA) for Toxics Use Reduction, the Toxic Use Reduction Institute (TURI) at the University of Massachusetts at Lowell, the Department of Environmental Protection's TUR programme, an Administrative Coordinating Council, an Advisory Board and a Science Advisory Board (Becker \& Geiser, 1997).

The state's primary strategy for motivating implementation of TUR plans is not based on traditional 'control' strategies such as inspections and fines. Instead, the Department of Environmental Protection (DEP) routinely refers firms to the Office of Technical Assistance for Toxics Use Reduction (OTA), an agency that provides free, on-site and confidential engineering assistance to identify and implement toxics use reduction opportunities. DEP also regulates Toxics Use Reduction Planners, the professionals accredited to certify TUR plans.

OTA and TURI provide tools to industry to learn how to reduce their own toxics. In addition to providing information on specific technical options for certain industries, these agencies help build the internal capacity of firms through training, educational materials and seminars. The state also serves as an "information and knowledge network-broker" (Lanou \& Laws, 1999, p. 23) for gathering and distributing information on new strategies for pollution prevention. In this regard, state agencies serve as facilitators of experimentation and learning about new technological processes.

TURA is much more focused on self-monitoring, planning and technical assistance than policing. The underlying rationale of TURA is that firms that are required to take a close look at their toxics-using processes will calculate the costs of using and disposing of these toxic chemicals, identify reduction opportunities on their own and be motivated to implement opportunities because of their financial, environmental and health and safety benefits. In addition, TURA provides for the public to petition and request DEP to review TUR plans and allows the public to bring an action against firms alleged to be in violation of the 
Table 1. Facility involvement in TUR activities

\begin{tabular}{lcc}
\hline Activity & $\begin{array}{c}\text { Percentage of respondents 'very involved' in activity } \\
\text { Before TURA }\end{array}$ & \begin{tabular}{c} 
After TURA \\
\hline Tracking quantities of wastes generated
\end{tabular} \\
$\begin{array}{l}\text { Tracking quantities of chemical used } \\
\text { Establishing a corporate or facility }\end{array}$ & $49 \%$ & $89 \%$ \\
$\quad$ environmental team & $24 \%$ & $90 \%$ \\
Setting goals for waste reduction & $24 \%$ & $68 \%$ \\
Reviewing changes in production & $30 \%$ & $73 \%$ \\
$\quad$ processes for their environmental, & & $76 \%$ \\
health and safety impact & $21 \%$ & $52 \%$ \\
Allocating environmental costs to & & \\
processes or products
\end{tabular}

Source: Abt Associates (1997).

Act (Cooke \& Berry, 1991; TURA §18). This creates another source of motivation, albeit currently a weak one, for firms to implement their TUR plans.

TURA in essence seeks to advance precautionary decision making and the simple idea that decision makers should act in advance of scientific certainty to reduce environmental hazards as much as possible (Tickner \& Raffensperger, 1998). TURA does not ask 'how much is safe?' or 'how much can we afford?' but rather, how much contamination can be avoided and what alternatives exist to a product or activity (Tickner, 1998). The precautionary principle catalyzes actors to address more fundamental questions of how they can behave in the most environmentally friendly ways in their production processes. When the precautionary principle is adopted as a management tool in regulatory decision making, significant energy can be devoted to the development of proactive rather than reactive regulation (Tickner, 1999; O'Riordan \& Jordan, 1995).

\section{The Impacts of TURA}

According to TURI, 943 firms have participated in the TUR programme to date. Four hundred and fifty of these firms have left the programme for a variety of reasons, most often because they have reduced or eliminated the use of the listed toxic chemicals below reportable levels (TURI, 2002). In June-July of 1996, Abt Associates surveyed 434 participating firms to measure and assess the TUR programme's performance. ${ }^{3}$ The survey results indicate that a large number of firms increased their involvement in key areas of environmental management.

As shown in Table 1, firms participating in TURA have tracked, set goals for, and allocated costs to their use of listed chemicals. Managers report increased internal awareness and improved monitoring of toxics use, and the development of systems for better managing toxic chemical use and emissions. TUR plans also lead to reductions in byproducts and emissions, as will be discussed below. Of the firms that implemented projects proposed in their TUR plans, $61 \%$ reported that they had decreased their toxics byproduct generation and $67 \%$ responded that they had reduced their toxic chemical use since 1990 (Becker \& Geiser, 1997). At the same time, of the firms that did not implement any of their proposed TUR projects, $61 \%$ reported that byproduct generation had increased or remained unchanged and $66 \%$ reported that toxic chemical use had increased or remained unchanged since 1990 (Becker \& Geiser, 1997). Clearly it 


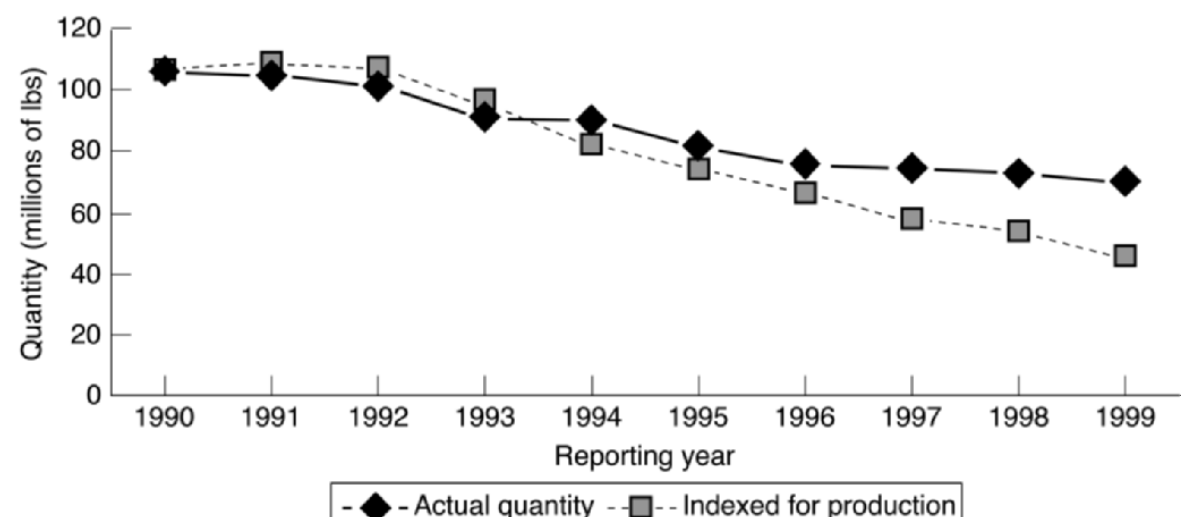

Figure 1. Toxic chemical byproduct generation. Note: Chemical byproduct generation is for 'Core Group' firms and chemicals. Source: Data from the Toxics Use Reduction Institute (2002).

is not enough to report emissions or to write a TUR plan. Firms must make real commitments of time, staff, and money to implement toxic use reduction.

DEP's data on Core Group performance indicate that the quantities of toxic byproducts declined between 1990 and 1999 by 34\%, despite a 40\% overall increase in industrial production in the state. ${ }^{4}$ When the effect of increased production is considered, the normalized reduction in byproduct generation was over 57\% (see Figure 1).

Despite increases in total chemical use in the state between 1994 and 1997, these increases did not overwhelm progress toward reducing toxic chemicals used in production. As Figure 2 shows, actual chemical use declined by $11 \%$ between 1990 and 1999. When adjusted for production increases, normalized reduction was $41 \%$ in the state, while national consumption of the top 100 chemicals continued to increase significantly.

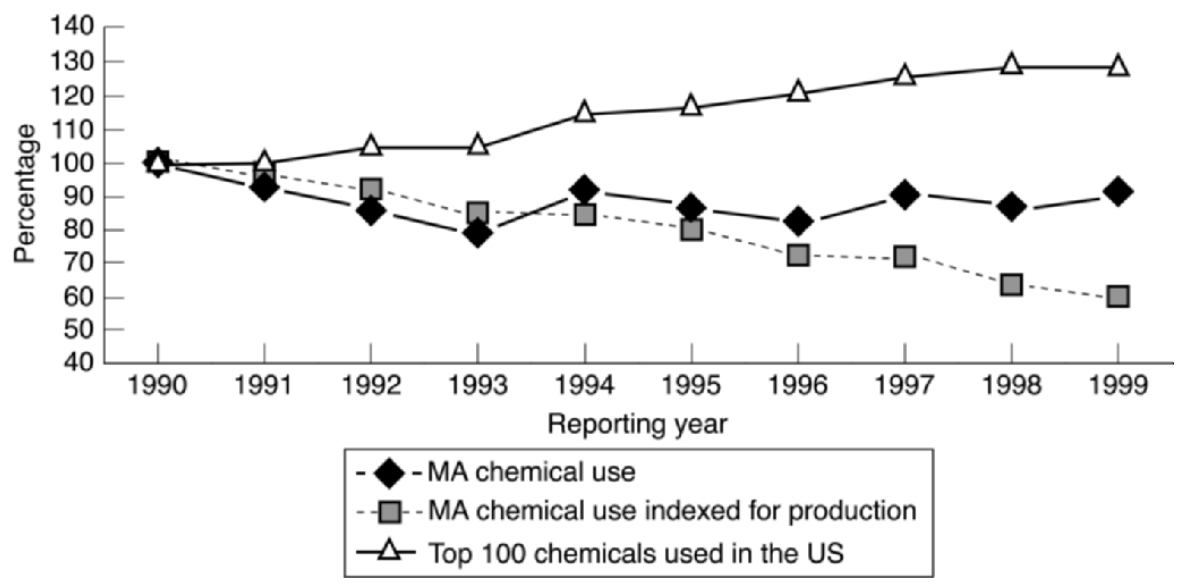

Figure 2. Percentage change in chemical use. Source: Data from the Toxics Use Reduction Institute (2002) and American Chemistry Council (2002). 


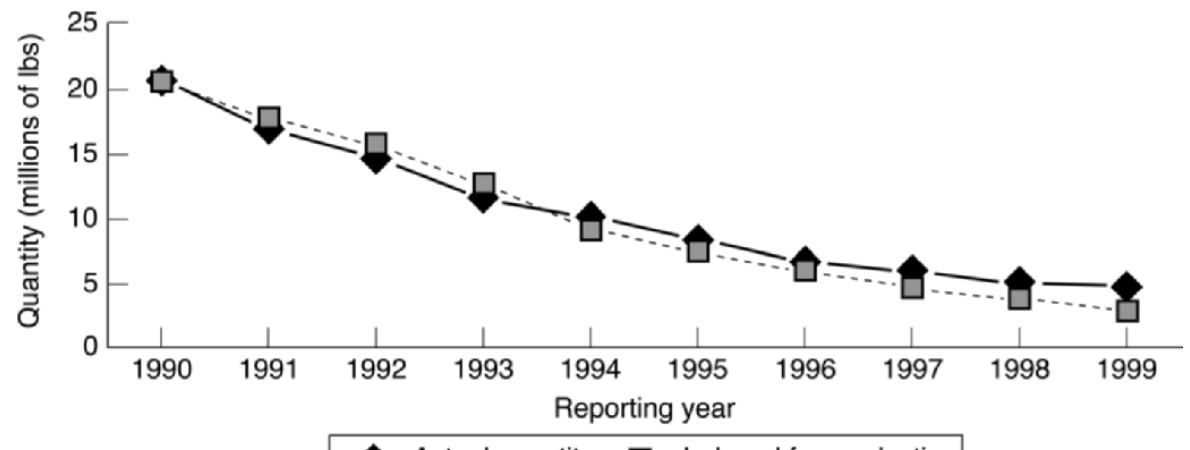

- Actual quantity - $\square$ - - Indexed for production

Figure 3. On-site releases. Source: Data from the Toxics Use Reduction Institute (2002).

Although there have been clear reductions in byproduct and total chemical use, TURA's goal of a 50\% reduction in byproducts between 1987 and 1997 was not achieved. Nonetheless, quantities of on-site releases to the environment were reduced by $80 \%$ by 1999 under TURA. When adjusted for production increases, on-site releases were reduced by $87 \%$ (see Figure 3 ).

When compared to the Toxic Release Inventory (TRI), another pollution prevention success story (Hearne, 1996; Fung \& O’Rourke, 2000; Karkkainen, 2001), TURA's achievements remain impressive (see Figure 4). For the last five years for which comparable data are available, TURA has out-performed the TRI on emissions reductions.

TURA has also been cost effective. In December 1996, Abt Associates conducted a cost-benefit analysis of TURA which showed that total costs (including costs of compliance and capital investments) were $\$ 76.5$ million in 1995, while total monetary benefits were $\$ 90.5$ million (Abt Associates, 1996). If non-monetary benefits such as gains to human health and ecological conditions had been included, the analysis would have shown TURA to be even more cost effective.

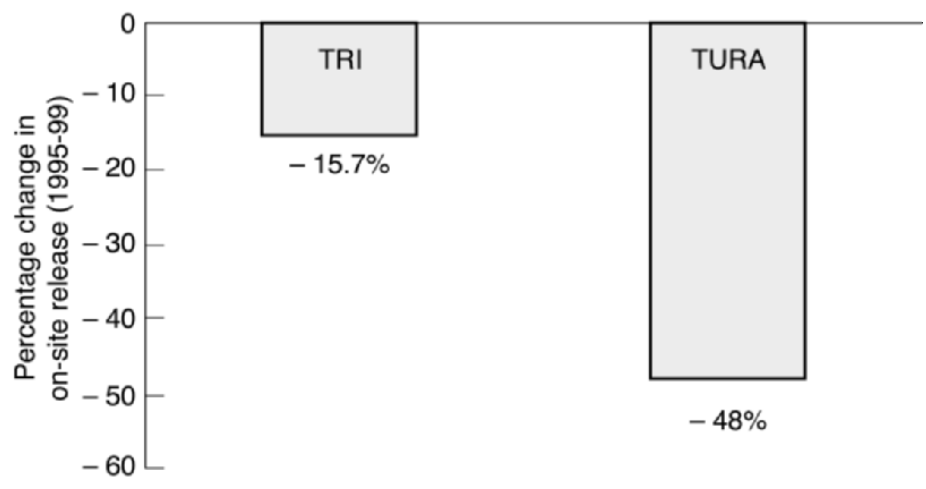

Figure 4. Comparison of TURA (Massachusetts) with TRI (nationwide) in On-site Releases between 1995 and 1999. Note: TURA listed chemicals include the entire TRI list. Thus, the study compares very similar lists of chemicals used in Massachusetts Core Group firms with national firms. Source: Data from the USEPA (2002) and Toxics Use Reduction Institute (2002). 


\section{Driving Innovation through TURA}

Describing the mechanisms of planning, accounting and decision making in TURA still does not explain the underlying dynamics which motivate firms to reduce toxics. Many factory managers originally viewed TURA quite critically, stating that they saw little value in TURA planning (Greiner, 1994; Lanou \& Laws 1999). The Associated Industries of Massachusetts (AIM) continues to oppose TURA, viewing it as an intrusion and burden on business decision making.

As Greiner (1994) found in a study of TURA firms, most company managers initially opposed TURA's planning requirements and viewed them as simply 'a compliance effort'. In interviews, firm managers asserted that toxics use reduction plans had "no benefit", were of "no use", "will not help us", and "we will get no money savings from doing toxics use reduction". Firms responded to TURA in four primary ways: escape compliance, ritual compliance, ambivalent compliance and beneficial compliance. Only one in 10 firms studied by Greiner viewed TURA planning as positive. Firms generally "did not believe that there was any need to change their chemical use and waste generation practices" (Greiner, 1994, p.13). Companies across the US continue to oppose programmes like the Toxic Release Inventory (TRI) and TURA. They generally do not support public disclosure, are often sceptical of government technical assistance and nervous to allow regulators in to 'look around', and almost always oppose statutes that require increased planning.

So why then has industry implemented toxics use reduction in Massachusetts? Perhaps other laws are actually driving the toxic reductions? National laws could be at work. This is unlikely as Massachusetts out-performed virtually every other manufacturing state in the country on TRI reductions, ranking as the number four state in on-site release reductions of TRI chemicals between 1995 and 1999 (EPA, 2002). Perhaps it is not government policies or regulations at all? Technological changes may be driving reductions in toxic chemical use that would have happened regardless of TURA. This seems unlikely as few other states have been able to match Massachusetts reductions in toxics without similar toxic use reduction or pollution prevention planning requirements. Perhaps it is simply that Massachusetts' industrial base has shifted in a way that leads to reductions in chemicals? This is unlikely as well as only 'Core Group' firms that have stayed within the programme during the 1990s have been studied here. Perhaps TURA is overstating toxic reductions as firms are lying about their chemical use and reductions. This also appears unlikely, as there is no apparent benefit to misstating chemical use, and even distortions would largely normalize out over the years. ${ }^{5}$

The hypothesis in this study is that despite the opposition and animosity of industry, TURA has been able to motivate industry to reduce toxics use through two mechanisms: mandatory planning and learning support. Forcing firms to better understand their processes (and the costs of these processes) and helping them identify options for pollution prevention through training, case studies of leading firms and publications, has led to an atmosphere of innovation and learning in the state which helps even reluctant firms change. 


\section{Mandatory Planning}

The initial attitude of factory managers to TURA planning requirements contrasts starkly with surveys of firms having completed the planning process (Becker \& Geiser, 1997). After conducting TURA plans, firms realized that there were benefits to developing process flow diagrams, conducting materials balances, identifying eco-efficiency options and receiving training on developing cross-functional environmental teams. To this day though, firms remain reluctant to attribute positive impacts or influences to TURA (Lanou \& Laws, 1999).

It thus appears necessary to require companies to create planning teams, to conduct assessments of production, to engage workers in these discussions and to assess the financial costs and benefits of production changes. TURA's mandatory requirements, combined with training and information sharing, have helped firms overcome the first barrier to pollution prevention, realizing the need to change. TURA helps firms recognize that they can change their production processes to reduce toxics and save money. TURA quite simply helps get managers' attention and focuses them on toxics reduction.

As Lanou \& Laws (1999) show in their study of Printed Circuit Board manufacturers under TURA, mandatory planning leads firms to identify ecoefficient options for reducing toxics emissions. TURA is well designed to help firms discover ways to reduce the use of a specific chemical or to switch to an alternative chemical, as the TURA planning process shines a light on chemical uses. TURA creates a pressure on firms to think about, and plan for, changes in chemical uses, and it gives them a framework for evaluating and improving operations.

But more interestingly, TURA planning requirements also motivate firms to develop systematic procedures for tracking and reducing chemical and other resource uses. Lanou \& Laws (1999) identify a series of deeper innovations among electronics firms including the development of chemical tracking systems, preventive equipment maintenance programmes, water conservation programmes and new environmental accounting systems. It thus appears that by commanding firms to plan for specific chemical use reductions, TURA has been able to motivate deeper, more systematic changes that support continuous process improvements and that support more extensive production process changes.

It is hypothesized that there is a need for this 'command' component in TURA. However, the focus is not command-and-control, but rather a sort of 'command-and-innovate' regulation. Regulators do not specify the technological answer to the problem, but rather express a faith in the ability of firms to find technical solutions if they take a systematic look at their processes. Some analysts and policy makers have argued that market signals should serve this same purpose. However, it appears to us that industry consistently fails to implement even the 'low hanging fruit' of economically efficient pollution prevention options. As one manager in Greiner's study (1994, p. 88) admitted, "We've got to be dragged kicking and screaming" to do toxics use reduction. TURA requires companies to conduct self-evaluation and technological alternatives assessment needed to acquire information on both problems and possibilities for environmental innovations. As can be seen in Table 1, a high percentage of firms ultimately participate in these activities once motivated. 
This process is distinct from traditional command-and-control regulation. TURA moves beyond requiring specific technologies or performance standards, to motivating a process for reducing environmental impacts. Actuating this process of planning, learning and implementing is key to environmental innovation.

\section{Learning Support}

One key limitation of command-and-control regulation is its inability to gather information on complex and continuously changing industrial practices (Dorf \& Sabel, 1998). Contrary to the assumption in traditional regulation that the government can know the answer to pollution problems, regulatory agencies rarely have sufficient knowledge or information to deal with rapidly changing technical or managerial problems. Market-based mechanisms face similar problems despite their greater flexibility and responsiveness. Under complex and changing conditions, "problems outside a regulated zone frequently become as significant as those within it" (Sabel et al., 2000). Effective regulatory programmes thus require continual processes for acquiring updated information. Learning processes are needed to help actors achieve goals by correcting errors, solving problems in new ways and developing knowledge in dealing with internal processes and external stimuli. As a number of analysts have noted, neither command-and-control, nor market-based approaches, are well suited to institutional learning or adaptation to new information (Karkkainen, 2001).

Fiorino (2001) and Glasbergen (1996) propose three forms of learning as critical to improved environmental policy: technical learning, conceptual learning and social learning. Technical learning involves the search for new policy instruments (such as the advent of pollution trading). Conceptual learning focuses on redefining policy goals, problem definitions and strategies (such as the switch to pollution prevention from pollution control). Social learning involves new interactions and relations between actors that help create an environment supportive of identifying solutions to policy problems. TURA builds on technical and conceptual learning, but ultimately helps to advance Fiorino's vision of social learning. Relationships between regulators and industry are transformed, implementation occurs not through command but through joint exploration and information sharing, and uncertainty is acknowledged and accepted as a reality of problem solving. TURA provides a more flexible process, ripe with dialogue and learning, that encourages technical innovation.

Lanou \& Laws (1999, p. 22) similarly show that TURA supports a kind of 'organizational learning' by engaging "firms in a process of discovery and learning to seek out innovative ways to reduce their use of toxic chemicals". On the most basic level, TURA helps firms identify simple options for reducing specific chemical uses or emissions. Lanou \& Laws, however, are interested in deeper learning than these discrete, one-off, eco-efficiency changes. They argue that policies should, and TURA in some cases does, support a process of 'double-loop' learning (Argyris \& Schon, 1996) in which firms explore, experiment and learn new ways to continuously manage their operations. TURA motivated innovations, such as new chemical tracking and financial accounting systems, have supported systematic and on-going inquiry, and improved capacities to monitor performance and processes for developing further improvements. 
Unlike traditional regulatory approaches, the requirements of mandatory reporting and planning provide actors with a useful learning process. Periodic reporting and TUR plan preparation help firms re-evaluate their production processes. Many top managers, previously unaware of the volumes of toxic chemicals used, are surprised at the information generated by TURA requirements (Becker \& Geiser, 1997). As one example, Dennis Prifti, vice president of Fit to Print Advertising Inc., which successfully converted its printing processes from solvent-based inks to ultraviolet (UV) cured inks notes, "We just were not aware that there were environmental benefits from UV as well" (DEP, 2000). By obtaining a better understanding of flows of toxic materials through the TUR planning process, firms have the opportunity to reduce toxic chemical use at certain points in their production processes and to reduce operational costs. ${ }^{6}$ Annual reporting also spurs firms to periodically develop new knowledge about production processes and toxics use. As Table 2 highlights, the process of TUR planning increases management attention to environmental issues, improves management techniques for dealing with these issues and supports implementation of TUR innovations.

In addition to internal learning, assistance from outside institutions can also lead to the enhancement of learning through pooling of information on innovations and disseminating knowledge on new environmental strategies. The Office of Technical Assistance for TUR (OTA) and the Toxic Use Reduction Institute both play this critical role in providing external assistance and knowledge sharing. Since its establishment, OTA has conducted more than 1400 site visits to approximately 600 firms to support toxics reductions. As an active agent of TUR technology transfer, OTA has sponsored over 200 conferences, workshops, and other events targeted at chemical users in industry. As Becker \& Geiser (1997) assert, "OTA has been a pioneer in many technical transfer programmes and outreach projects ... used as models by other states". In addition, OTA has actively used TURA for 'basic learning' and for "outreach purposes such as targeting and education, knowledge transfers, site visits, etc." (Personal communication with Walter Hope, TUR programme Branch Chief, 10 April 2001).

The Toxics Use Reduction Institute (TURI) also plays an important role in knowledge sharing. Established by TURA in 1989, TURI has worked in conjunction with DEP and OTA as a multidisciplinary research, education and technical support centre. The main purposes of TURI are "to provide general information about and actively publicize the advantages of and developments in TUR" (TURA §6-A) and "to establish courses, seminars, conferences and other events, and reports, updates, guides and other publications, and other means of providing technical information for toxics users" (TURA §6-B). TURI staff assert that "TURI's most important roles are training for planners, bringing planners together for demonstration of new technologies and information in terms of fact sheets and research projects" (Personal communication with Heather Tenney, technical researcher for TURI, 2 May 2001).

In order to meet the mandates of TURA, the Institute initiated the Cleaner Technology Demonstration Site Program (CTDSP) in 1995. CTDSP has conducted more than 20 projects in various sectors over the last five years, promoting the adoption of cleaner technologies by showcasing innovations. Since the programme's inception, over 600 environmental managers have visited showcase companies to learn about their environmental innovations. According to Heather Tenney: 


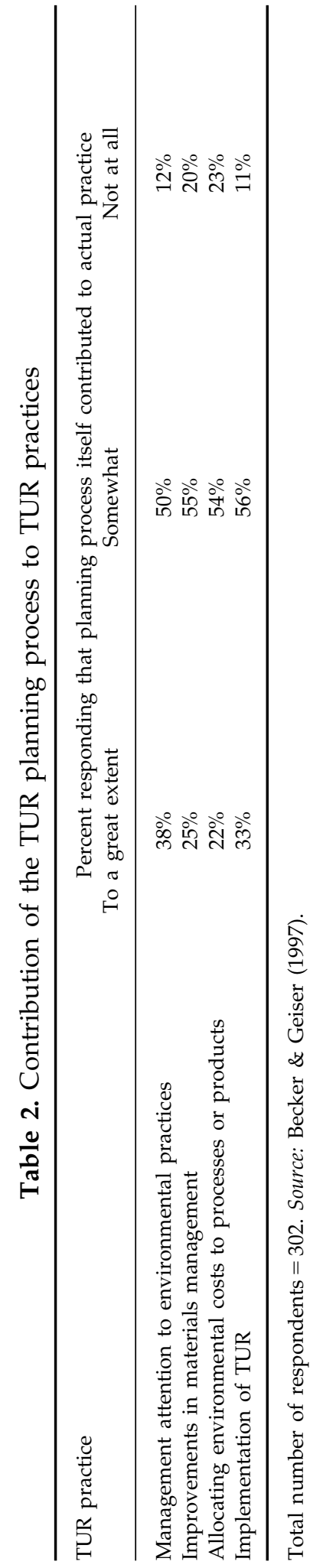


TURI has analyzed and used this information in many ways. We look to see if we are making overall progress reducing toxics. We look at a specific chemical or industry sector and see what is going on. We look to see if specific types of TUR are occurring. And we give the information to concerned citizens and try to help them understand it. We use the data both to see what's happened in the past and try to use it to guide the future. (Personal communication, 18 April 2001).

CTDSP has facilitated the learning process among TURA firms. As Table 3 shows, CTDSP has conducted a number of case studies on TUR success stories documenting firm actions to reduce toxics. CTDSP has contributed to the success of TURA by establishing an easy-to-access pool of information, through which the best environmental performers demonstrate their achievements, while other firms learn practical TUR techniques. Firms do not rely exclusively (or sometimes at all) on these state sources of information on toxics reduction options. However, state training and information dissemination are reported to be key to firm methods for approaching TUR, firm managers' attitudes towards TUR and networking (Greiner, 1994; Lanou \& Laws, 1999).

In addition, TURI provides training programmes for individuals who wish to be accredited as TUR planners. This training provides participants with the knowledge and skills essential to develop TUR plans, and state-of-the-art TUR technologies. TURI's services are available for free to firms seeking help with alternatives to toxic chemicals. Moreover, TURI develops and examines tools that both firms and public agencies can use to measure, promote, plan and assess TUR techniques. Together with OTA, TURI contributes to developing knowledge about TUR and disseminates it widely to firms and the public.

For regulatory agencies, TURA provides a way of overcoming the problem of gathering information on toxic chemical use in Massachusetts. Under traditional approaches, regulatory agencies shoulder the burden of collecting information for effective regulation. Regulatory agencies often face difficulties gathering this information as firms are reluctant to reveal it, and independent collection is costly, time consuming and sometimes impossible. By making reporting mandatory through TURA, while protecting confidential business information, the regulatory agency can accumulate and update knowledge about industrial uses of toxic chemicals and TUR strategies. Since the first TURA data became available, DEP has been working to create an extensive database to identify obvious reporting and entry errors, and to identify changes in management systems that would improve the utility of the data at the production unit level. This will allow both DEP and firms to determine to what extent changes occur (and in which firms) and, in turn, support improved environmental management.

\section{Limitations of TURA}

Although TURA has supported significant toxics use reduction in Massachusetts, it is limited in a number of ways. First, TURA is limited in its scope of influence. TURA does not regulate industries or commercial enterprises that use small amounts of listed chemicals. Nor does it include firms that have fewer than 10 employees or firms outside the listed SIC codes even if they use listed chemicals. The cumulative impact of small firms and non-point sources is 


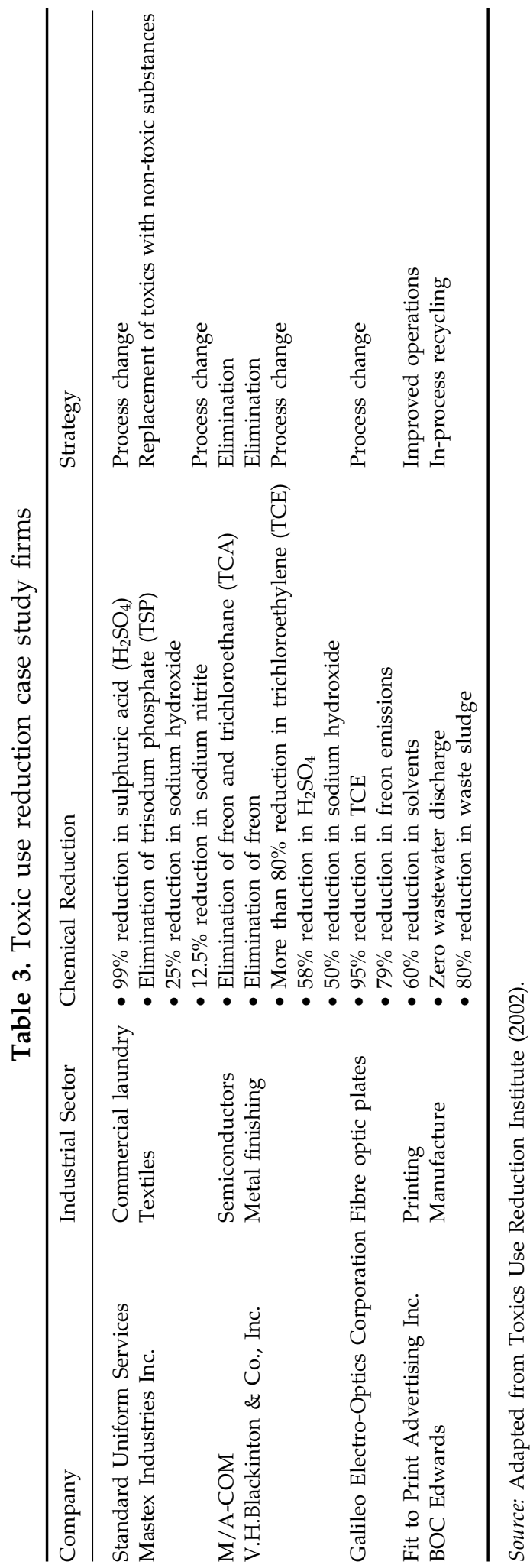


increasingly important. However, these firms are extremely difficult to monitor or technically assist.

TURA is also limited in its ability to motivate firms to implement their toxics use reduction plans. Firms can, and often do decide against implementing their plans. As Walter Hope notes, "While in many cases it makes sense to implement a change, in some others it may not ... While saving the environment or doing the right thing is one motivator for companies to implement (TUR plans) ... saving money seems to be the driving factor" (Personal communication, 20 April 2001). Thus, TURA faces a predicament of how to motivate firms to implement toxics use reduction plans without falling into the old problems of command-and-control regulation. Any attempt at mandatory implementation might motivate firms to withhold information or misrepresent their materials accounts and options for reductions in order to avoid implementation.

TURA is also limited in its facilitation of public participation in environmental protection efforts. In theory, communities can obtain TURA data from the state and they can request a regulatory review of a specific TUR plan. However, no community member has successfully used the resident petition process to date (Ken Geiser, personal communication, 15 October 2001), and there is little room for public participation in evaluating TURA data, pollution prevention options or in disseminating best practice results. Previous studies of information-based environmental regulation posit that public pressure can be a key driver motivating pollution reductions (Grant, 1997; Konar \& Cohen, 1997; Tietenberg \& Wheeler, 1998; Afsah et al., 2000; Fung \& O'Rourke, 2000). Although TURA depends more on business participation than public participation, without public pressure, it will likely face a plateau of effectiveness, where uncommitted firms will continue to submit plans, but never implement them.

\section{Conclusions and Policy Implications}

TURA is distinct from existing regulatory programmes in how it requires firms to self-evaluate and plan for process improvements, supports implementation through technical assistance and focuses on precautionary action and prevention rather than control. Improved processes of learning have also been critical to the Act's success in motivating firms to innovate for the environment. Taken together, these factors have supported incremental innovations in industry that may point the way toward policies to support even greater environmental innovation.

Despite its limitations, TURA has achieved important successes in toxics use reduction in Massachusetts, at the same time that industry has continued to expand. This success can provide insights for future regulatory policies that seek to motivate firms to better track their full life-cycle impacts, identify possible toxics use reduction options and implement innovative changes in production.

TURA meets virtually all of the criteria of Porter \& van der Linde's (1995) 'innovation-friendly regulation'. It focuses on outcomes, rather than specific technologies; it is stricter rather than lax, mandating clear firm requirements for planning; it employs market incentives, pushing firms to evaluate costs and benefits of pollution prevention options; it requires industry participation in 'standard setting'; and it develops technical capabilities among regulators. At the same time, TURA seems to support many of the processes that Ashford (2000) asserts are central to catalyzing innovation: regulatory goals should be clear 
while the means of complying are flexible, and regulations should be coupled with firm willingness to change, opportunities for change and capacities. TURA supports exactly these processes through mandatory planning and learning support. While TURA's first level of innovations are incremental, the actions which TURA motivates may lead firms to deeper innovations and re-thinking of production.

Future regulations could of course do more to promote innovations for the environment. Nonetheless, TURA provides some markers for this road forward. For instance, TURA makes clear that regulation can and should promote industry self-monitoring and exploration of process improvements. Regulatory implementation should be supported through new mechanisms of transparency, accountability and learning, rather than rigid technology-based standards. Perhaps most importantly, the history of TURA shows that regulations need to transform the attitudes of managers, and then support their efforts at change. Regulations can provide some 'commands' to motivate action, and some assistance to guide explorations. TURA's basic requirements of reporting and planning can motivate creative thinking, exploration, experimentation and 'surprises'. TURA represents the potential for what could be termed a sort of 'command-and-innovate' regulation.

In order to facilitate real learning and to move firms beyond one-time, eco-efficiency improvements, it is necessary to design policies that advance serious factory self-analyses and exploration of the widest range of options for toxics reductions. Policies should motivate firms to focus their attention and skills on problem solving, to convince them that there is a problem and to help them recognize that there are alternatives to their current processes. Ultimately policies should help firms institutionalize learning processes in management systems or other strategies to set in motion a process of continuous improvement. Government assistance and incentives can be critical in supporting firms in implementing their plans.

There remains a need, however, to create additional mechanisms and incentives to motivate firms to innovate for TUR. Greater public disclosure of TUR data might create one such motivation. Periodic dissemination of TURA data and a list of 'worst performers' might be an effective means to draw public concern into the universe of TURA. TURA data could also easily be used to 'benchmark' firms in similar industries to publicly identify leaders and laggards. Benchmarking with TURA-like data could help firms better assess their current performance relative to their competitors, and help them identify possibilities for future improvements. Public disclosure of these comparisons (for both embarrassment of the laggards and encouragement of the leaders) would create further incentive for firm innovations, and help community members and NGOs play a watchdog role in toxics reductions.

TURA planning and reporting processes could also be used to identify substances that could be reduced through traditional regulations that ratchet down emissions limits. When several firms show it is possible to reduce a specific chemical, that chemical could be targeted for stricter regulation, thus levelling the playing field for all firms and benefiting leading firms. This might also create incentives for firms to implement their plans to stay ahead of regulations.

At present very little is known about how innovation occurs in industrial enterprises, or how it can be best motivated and supported. This paper has 
presented preliminary research on the Toxics Use Reduction Act, and admittedly preliminary hypotheses on its underlying mechanisms. Further research is needed on the processes driving and supporting innovations inside firms to change production to reduce pollution. Nonetheless, TURA presents an important case of a regulatory initiative that appears to promote innovation in industry. Building further on the principles of mandatory planning, firm selfevaluation and learning seems a promising strategy to support future initiatives for environmental innovation.

\section{Notes}

1. In addition to this primary objective, the Act states five related goals: (1) To establish toxics use reduction as the preferred means for achieving compliance with any federal or state law or regulation pertaining to toxics production and use, hazardous waste, industrial hygiene, worker safety, public exposure to toxics or releases of toxics into the environment and for minimizing the risks associated with the use of toxic or hazardous substances and the production of toxic or hazardous substances or hazardous wastes; (2) To sustain, safeguard and promote the competitive advantage of Massachusetts businesses, large and small, while advancing innovation in toxics use reduction and management; (3) To promote reductions in the production and use of toxic and hazardous substances within the commonwealth, both through the programmes established in section three of this Act and through existing toxics-related state programmes; (4) To enhance and strengthen the enforcement of existing environmental laws and regulations within the commonwealth; and (5) To promote co-ordination and co-operation between all state departments and agencies administering toxics-related programmes (www.state.ma/legis/laws/mgl).

2. A firm must be in an industry that falls within Standard Industrial Classification (SIC) codes 10 through 14 (mining), 20 through 39 (manufacturing), 40 and 44 through 49 (transportation), 50 and 51 (wholesale), and 72, 73, 75, and 76 (certain services) (TURA \$10). A firm must employ 10 or more full-time workers, and must annually manufacture or process at least 25000 pounds or 'otherwise' use at least 10000 pounds of any chemical listed on a special state list made up of chemicals on the TRI and federal Superfund lists. A firm that meets these three criteria is considered a 'large quantity toxics user (LQTU)'.

3. Under contract to TURI, Abt Associates conducted a survey of large quantity toxics users and a benefit-cost analysis of the TURA programme. They conducted a census rather than a random sampling of the subjects to gather the input of the greatest number of firms.

4. Consistent measurement of TUR progress is complicated by changes in requirements over the reporting period (DEP, 2000). Chemicals have been added and de-listed during the life of the programme, and thus some TURA filers have entered or left the reporting universe due to changes in requirements. TUR progress in this paper is assessed by analyzing only 'Core Group' industries that have remained within reporting requirements between 1990 and 1999.

5. As one TURI staff member explained, "They [TURA firms] don't gain anything by falsely reporting reductions, but they would lose something if they got caught reporting incorrectly. Studies have been done on data accuracy, and generally even though the data are not perfect, it was shown there was no bias for over-reporting reductions" (Personal communication with Heather Tenney, TURI, 2 May 2001).

6. According to a survey conducted in 1997 by TURI, $67 \%$ of respondents reported that they experienced direct cost savings (e.g. on materials use or waste disposal) from TUR actions (Becker \& Geiser, 1997).

\section{References}

Abt Associates (1996) Benefit-cost analysis of the Massachusetts Toxics Use Reduction Act, report to the Toxics Use Reduction Institute, UMASS-Lowell.

Abt Associates (1997) Survey evaluation of the Massachusetts Toxics Use Reduction Program, report to the Toxics Use Reduction Institute, UMASS-Lowell.

Ackerman, B. A. \& Stewart, R. B. (1985) Reforming environmental law, Stanford Law Review, 37, p. 1333. 
Afsah, S., Blackman, A. \& Ratunanda, D. (2000) How do public disclosure pollution control programs work? Evidence from Indonesia, Discussion Paper 00-44 (Washington, DC: Resources for the Future).

American Chemistry Council (2002) The Business of Chemistry in the USA: Performance and Outlook, Data tables (Arlington, VA: American Chemistry Council).

Argyris, C. \& Schon, D. (1996) Organizational Learning II: Theory, Method, and Practice, in: E. Schein \& R. Beckhard (Eds) Addison-Wesley Series on Organizational Development (Reading, MA: Addison-Wesley).

Arora, S. \& Cason, T. N. (1996) Why do firms volunteer to exceed environmental regulations? Land Economics, 72, pp. 413-432.

Arora, S. \& Cason, T. N. (1999) Do community characteristics influence environmental outcomes? Evidence from the toxics release inventory, Southern Economic Journal, 65(4), pp. 691-716.

Ashford, N. (2000) An innovation-based strategy for a sustainable environment, in: J. Hemmelskamp, K. Rennings \& F. Leone (Eds) Innovation-Oriented Environmental Regulation: Theoretical Approaches and Empirical Analysis (New York: Physica Verlag).

Ashford, N. (2002) Government and environmental innovation in Europe and North America, American Behavioral Scientist, 45(9), May, pp. 1417-1434.

Becker, M. \& Geiser, K. (1997) Evaluating Progress: A Report on the Findings of the Massachusetts Toxics Use Reduction Program Evaluation (Lowell, MA: Toxics Use Reduction Institute, University of Massachusetts at Lowell).

Cooke, S. \& Berry, D. (Eds) (1991) Massachusetts Environmental Law Handbook (Rockville, MD: Government Institute, Inc.).

Department of Environmental Protection (DEP) (2000) Office of Technical Case Studies Available at: http://www.state.ma.us/ota/casestud.htm (accessed 1 October 2001).

Dorf, M. \& Sabel, C. (1998) A constitution of democratic experimentalism, 98. Columbia Law Review, 98(2), p. 267.

Environmental Protection Agency (EPA) (2002) Toxics Release Inventory. Available at http:// www.epa.gov/tri/.

Fiorino, D. (2001) Environmental policy as learning: a new view of an old landscape, Public Administration Review, 61(3), pp. 322-334, May/June.

Fung, A. \& O'Rourke, D. (2000) Reinventing environmental regulation from the grassroots up: explaining and expanding the success of the toxics release inventory, Environmental Management, 25(2), pp. 115-127.

Glasbergen, P. (1996) Learning to manage the environment, in: Democracy and the Environment: Problems and Prospects, W. Lafferty \& J. Meadowcroft (Eds) (Cheltenham: Edward Elgar).

Grant, D. S. (1997) Allowing citizen participation in environmental regulation: an empirical analysis of the effect of right-to-sue and right-to-know provisions on industry's toxic emissions, Social Science Quarterly, 78(4), pp. 859-873.

Greiner, T. (1994) The environmental manager's perspective on toxics use reduction planning, Master's Thesis, Massachusetts Institute of Technology.

Hearne, S. A. (1996) Tracking toxics: chemical use and the public's 'right-to-know', Environment, 38(6), pp. 4-9, 28-34.

Karkkainen, B. C. (2001) Information as Environmental Regulation: TRI and Performance Benchmarking, Precursor to a New Paradigm? Georgetown Law Journal, 89, p. 259.

Konar, S. \& Cohen, M. A. (1997) Information as regulation: the effect of community right to know laws on toxic emissions, Journal of Environmental Economics and Management, 32, pp. 109-124.

Kraft, M. (1999) Making decisions about environmental policy, in: K. Sexton, A. Marcus, K. W. Easter \& T. Durkhardt (Eds) Better Environmental Decisions (Washington, DC: Island Press).

Laden, F. \& Gray, G. (1993) Toxics use reduction: pro and con, Risk-Issues in Health and Safety, Summer, pp. 213-234.

Lanou, S. \& Laws, D. (1999) Production and organizational learning: towards a new orientation for environmental policy, Environmental Technology and Public Policy Working Paper \#99-03, Massachusetts Institute of Technology.

National Academy of Public Administration (NAPA) (2000) Transforming regulation, in: Environment.gov: Transforming Environmental Protection for the 21 ${ }^{\text {st }}$ Century, pp. 31-43 (Washington, DC: NAPA).

O'Riordan, T. \& Jordan, A. (1995) The precautionary principle in contemporary environmental politics, Environmental Values, 4, pp. 191-212.

Porter, M. \& van der Linde, C. (1995) Green and competitive: ending the stalemate, Harvard Business Review, September-October, 73(5), pp. 120-134. 
Rondinelli, D. (2000) Rethinking US Environmental Protection Policy, PricewaterhouseCoopers Endowment for the Business of Government (Arlington, VA: PwC).

Sabel, C., Fung, A. \& Karkkainen, B. (2000) Beyond backyard environmentalism: how communities are quietly refashioning environmental regulation, Boston Review, 24(5), October/November, pp. 4-23.

Tickner, J. A. (1998) The precautionary principle and toxics use reduction, The Networker, 3(1), pp. 1-3.

Tickner, J. A. (1999) A map toward precautionary decision making, in: C. Raffensperger \& J. Tickner (Eds) Protecting Public Health and the Environment (Washington, DC: Island Press).

Tickner, J. A. \& Raffensperger, C. (1998) The precautionary principle: a framework for sustainable business decision-making, Corporate Environmental Strategy, 5(4), pp. 75-82.

Tietenberg, T. \& Wheeler, D. (1998) Empowering community: information strategies for pollution control. Working Paper in Frontiers of Environmental Economics Conference, Virginia.

Toxics Use Reduction Institute (TURI) (2002) TURA Data-A community guide to toxics information from Massachusetts' Toxics Use Reduction Act. Available at: http://www.turi.org/turadata/ (accessed 10 April and 1 November 2001). 